\title{
Mining
}

http://dx.doi.org/10.1590/0370-44672020740114

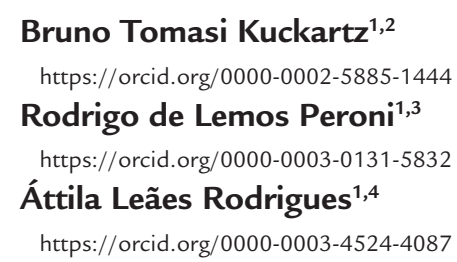

${ }^{1}$ Universidade Federal do Rio Grande do Sul - UFRGS, Departamento de Engenharia de Minas,

Porto Alegre - Rio Grande do Sul - Brasil.

E-mails: ${ }^{2}$ brukuck@hotmail.com, 300015547@ufrgs.br, ${ }^{4}$ attila.leaes@gmail.com

\section{Multi-stage dumping sequence - a feasible waste management alternative for open pit mining}

\section{Abstract}

Waste management and environmental aspects are progressively gathering attention in the mining industry. Mine planners must deal with increasingly complex tasks to balance between ore block schedules, waste disposal, operational cost and environmental reclamation. The mine incomes are generally related to mining and processing of the ore, thus most optimization researches regarding strategic mining usually focus mainly on ore extraction. Nevertheless, waste sequencing and disposal play an important role given that, in several situations in open pit mining, waste volumes are generally larger than ore volumes and must be moved to reach the buried and deeper ore bodies. In some cases, a significant percentage of operational costs is represented by waste haulage and disposal. Thus a careful planning strategy must be considered to minimize unnecessary expenses. Selecting locations for waste dumps is also a challenge. Many operational and technical aspects must be considered, not to mention the increasingly limiting environmental constraints. This definition can be very time consuming, and if it is not properly studied, may negatively impact the mine operation during its lifetime. This article investigates a new approach for mine waste management called the multi-stage dumping sequence (MSDS), suggesting the use of temporary waste dumps along the way to the final dump destination. Although this method requires material re-handling, which is considered a paradigm in mine industry, it certainly provides additional time to design and permit the final waste dump site and, if well planned, might even result in profit increases by reducing haulage distances in the first years of operation.

keywords: strategic planning, optimization, sequencing, waste handling. 


\section{Introduction}

Many aspects of mine planning optimization have evolved in recent decades. A large number of researches in strategic mine planning, supported by computer programming, have been published and presented optimum solutions to multivariable operational problems through robust optimization algorithms. Mine planning is the subject of several optimization studies ( $\mathrm{Li}$ et al., 2012), such as pit limit definition (Dagdelen, 2001; Dimitrakopoulos et al., 2007; Espinoza et al., 2013; Deutsch et al., 2015) and extraction sequencing (Caccetta and Hill, 2003; Dimitrakopoulos and Ramazan, 2003; AskariNasab et al., 2011; Waqar Ali Asad and Dimitrakopoulos, 2012; Ramazan and Dimitrakopoulos, 2013; Lambert et al., 2014).

In order to maximize the net present value (NPV) and assuming that profit and income are typically related to ore extraction/concentration/sales from the operation, most research regarding mine planning focuses on ore sequencing optimization more than waste handling. Waste management and sequencing have an important role in strategic planning, given that usually the volume of waste material is larger than ore.

Waste portions of the mineral deposit, by definition, have zero or non economical grade to justify sending it to the plant, therefore it does not provide any profit (Li et al., 2012), and must be sent to a proper destination, like a stockpile or straight to the waste dump, in most cases. The waste haulage from pit to its final destination, according to Lizotte and Bonates (1987), might represent more than $50 \%$ of the operational costs. Therefore, finding ways to reduce such costs is a task that must be

\section{Materials and methods}

The MSDS methodology consists of allocating a temporary dump site between the open pit exit and final dump location. The waste then is hauled to the temporary instead final dump until it reaches full capacity. Variables such as waste movement and re-handling rate, distance from pit exit to final dump site and temporary dumps, and distance between temporary dumps are considered in this study. targeted in mine planning, assuming its economic and strategic relevance.

Hekmat et al. (2008) highlight the importance of considering environmental issues besides technical and economic perspectives when defining the location of waste dumps, given its permanent character. Therefore, defining a proper location must comply with many conflicting aspects, such as environmental issues, geotechnical stability analysis, and geochemical and physical aspects. Authors such as Zinck (2004) and Ortiz (2017) state that the ideal location for waste dumps is not necessarily the best economic alternative or the choice that represents the lower cost option, but rather a solution that balances all these variables.

Some studies regarding waste rock sequencing optimization (AskariNasab and Ben-Awuah, 2011; Li et al., 2013; Graskoski, 2013; Fu et al., 2015; Fu et al., 2016; Li et al., 2016; Ortiz, 2017) have been published in the last few years. These articles proposed optimum solutions for waste sequencing throughout mixed integer programming (MIP), in a long-term planning basis. Li et al. (2012) presented a waste block sequencing to reduce total haulage distances considering multiple dump destinations, potential acid drainage issues, and also material re-handling as a boundary condition that must be avoided.

According to Dagdelen (2001), implementation of computer programming and stochastic algorithms to support strategic planning decisions are also gathering attention within the mining community. Other authors, such as Leite and Dimitrakopoulos (2007), Elkington and Durham (2011), Deutsch and Deutsch (2013) used such implementations to find optimum solutions in mine planning problems. These are robust tools that allow planners to test several variable combinations in hundreds of scenarios in a few minutes, providing a massive range of possible results to be evaluated and compared. Problems in the mining industry usually consist in solving multivariable questions and computer programming is proving to be a powerful planning aid.

This article is the continuation of a study presented in Kuckartz and Peroni (2019), which proposed a new method for waste disposal called a multi-stage dumping sequence (MSDS). This method allocates temporary waste dumps along the way to the final dump destination, and uses planned rehandling of the waste material at the beginning of operation. This approach provides additional time to find the best location for the final waste dump and to deal with preparation and licenses related to it. The main objective in this approach is to reduce waste haulage cost in the first years, as it reduces the haulage distance and consequently the investment in haul trucks and roads. Although an increase in unitary haulage cost is considered to re-handle material from/to temporary dumps, it is overcome by reducing haulage distances, resulting in NPV increases in the first years. Herein, the methodology uses an integrated mine planning and waste disposal sequencing, and an application to a real case study to demonstrate its applicability when carried out. Evaluation and comparison of MSDS against a conventional approach (not using a temporary dump) was made through a computer algorithm using Python in order to find the best possible solution to the proposed case.
For explanatory purposes and to highlight the differences between conventional and MSDS approaches, consider Figure 1, where the distance from the pit exit to the final dump location is " $\mathrm{X}$ ". In the conventional approach, waste rock would be hauled "X" distance during the life of the mine, avoiding waste re-handling, keeping fixed haulage distances outside the pit. In the MSDS approach, two stages will be considered to cover the distance " $X$ ": the first stage consists of hauling waste to a temporary waste dump distant "Y" from the pit exit; and the second stage consists in re-handling the waste material from the temporary waste dump to the final waste dump ("X minusY" distance).. For example, in Figure 1 (where $\mathrm{P}$ is the period from mine life), waste rock from P1 (W1) and P2 (W2) will be hauled at a distance "Y" from 
the pit exit, until reaches the temporary dump full capacity In P3 (example's last period), W3 is sent all the way to the final dump (distance " $X$ ") and W1 and W2, placed in the temporary dump stage, are also re-handled to the final position (which is hauled to a distance "X minus $Y$ ").
The sum of haulage distance is similar for both methods; however, in the MSDS approach, the total haulage distance in P1 and P2 (sum of distances) is lower if compared with the conventional method for the same period, which reduced the total haulage cost. As a consequence, haulage distances in later stages might increase and also increase haulage cost. However, when considering NPV calculations, there are penalizations by period (the further the period is, the greater the penalty), and the increased haulage cost in later stages will also be attenuated by period penalization, resulting in a lower final NPV cost.

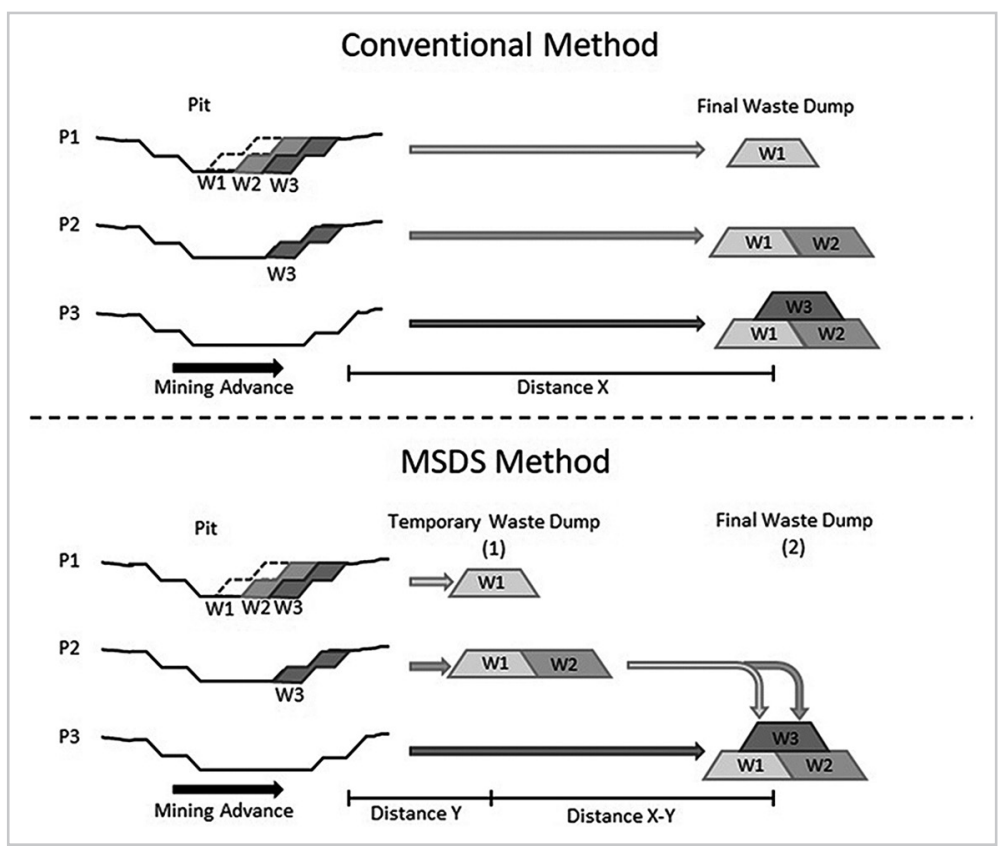

Figure 1 - Comparison between conventional and MSDS approaches, where "P" represents the period, "W" represents the waste material produced in each period and " $n$ " represents the number of dumping stages. Adapted from Kuckartz and Peroni (2019).

To test and illustrate the MSDS approach, a case study was conducted in a phosphate mine in Brazil. A portion of existing block model, representing a mine sector, was imported to the NPV Scheduler ${ }^{\circledR}$ software to build a mathematical open pit and scheduling sequencing for all blocks. Given the focus on waste management of this study and considering that all ore blocks are sent to the same location (i.e. processing plant) with a fixed haul distance for any tested scenario, all results shown here represent only costs related to waste block haul and loading outside the pit.

The base case was assumed to be the conventional approach. A pit exit and final dump location were established. The schedule considers the first 10-year period of production and the associated waste handling, also sequenced yearly.

There are several variables to be considered for a complete evaluation, such as haulage and loading cost, rehandling cost, distance from pit exit to final and temporary waste dumps, type and capacity of equipment (trucks and shovels) to be used, among others. In Kuckartz and Peroni (2019), some MSDS scenarios were tested, varying the period of re-handling operation and observing the cost NPV response to changes in haulage distance to the temporary dump; however, no optimization technique on such a parameter was considered at that stage.

In this study, an optimization algorithm was built using a Python implemented algorithm to find the best possible solution considering some variable fluctuations. The distance to the temporary waste dump and its rehandling rate were modified to find the lowest NPV cost possible.

The other parameters were kept fixed, such as haulage and loading costs, distance to final waste dump and temporary waste dump volume capacity, which was set to $30 \mathrm{Mt}$ of waste, representing 2 years of disposal operation. The temporary waste dump was placed over an area that will be mined in the future (after the 10 th year), and it is located between the pit exit and final dump location. Therefore, the temporary waste dump must be completely removed before the 10th year in order to avoid higher stripping ratios or delays in mining sequence.

Re-handling costs were considered to be equal to mining costs and did not include any additional general and administrative (G\&A) costs, since it is already paid by the current operation. The final dump is located $5 \mathrm{~km}$ away from the pit exit (according to the original base case mine planning), following the red line representing the haulage road, as shown in Figure 2 , and the annual waste movement is defined as 15 Mtpa. During the analysis, the temporary dump distance will occupy different spots by the road to the final dump location (varying from 0.5 to $4.3 \mathrm{~km}$ ) in order to find the position that results in the lowest NPV cost scenario.

The necessary number of trucks to accomplish the scheduled scenarios was calculated considering a utilization factor of $90 \%$ and mechanical availability of $85 \%$. Average truck speeds during laden and unladen displacement were also estimated in order to calculate truck production rates. 


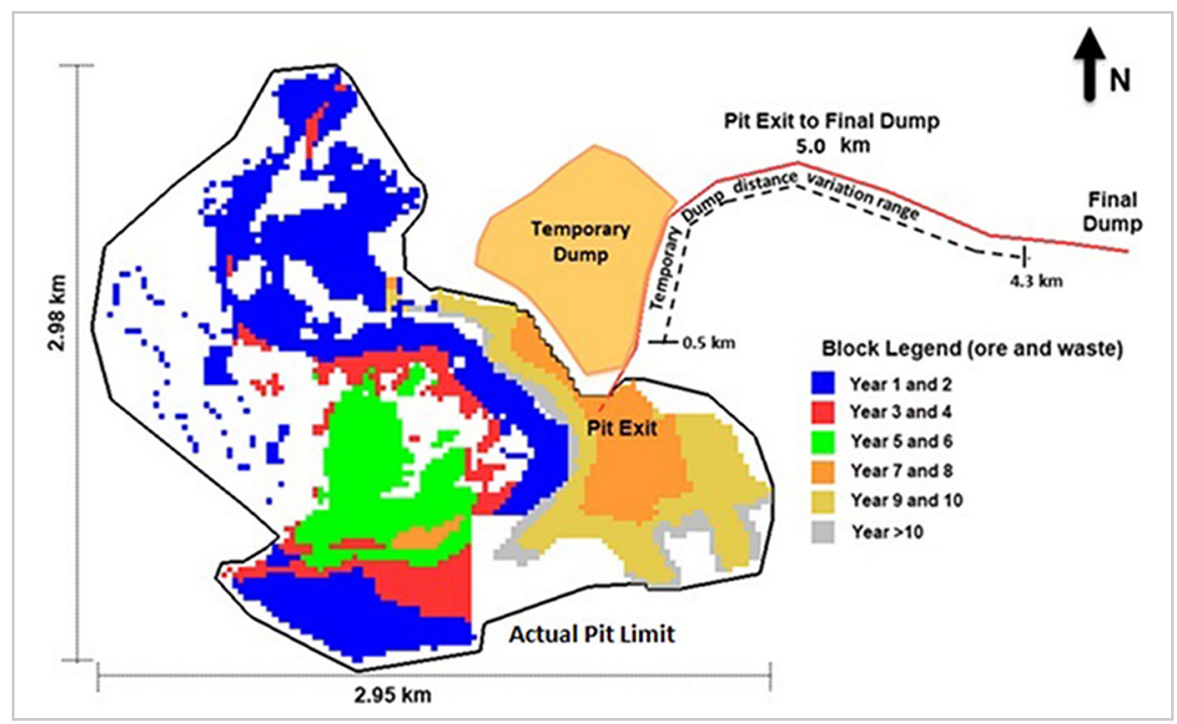

Figure 2 - Block schedule for the 10th year period and locations of the pit exit and final dump (5 $\mathrm{km}$ from pit exit) and temporary dump spot ranges. Illustrative picture (not to scale). Adapted from Kuckartz and Peroni (2019).

\subsection{Optimization algorithm implementation for MSDS}

The optimization algorithm for MSDS was implemented observing a few assumptions and later decision making.

Assumptions:

The algorithm to sequence the waste will respect the ore block schedule. The suggested optimization will not interfere with the already defined amount of material taken from the pit each year.

\subsection{Algorithm outputs}

The number of required trucks in each year to perform all hauling operations. This number of trucks is subdivided into the following: the number of trucks necessary to haul material from the pit to the temporary waste dump; the number of trucks necessary to haul material from the temporary to the final waste dump; and the number of trucks necessary to haul material from the pit to the final waste dump. The report is given by year.

The waste haulage schedule from the pit to the temporary waste dump, from the pit to the final waste dump, and re-handling from the temporary to

\section{Results}

The number of required trucks in each year to perform all hauling operations. This number of trucks is subdivided into the following: the number of trucks necessary to haul material from the pit to the temporary waste dump; the number of trucks necessary to haul material from the temporary to the final waste dump; and the number of trucks necessary to haul material from the pit
The material re-handling from the temporary waste dump to the final waste dump is postponed as much as possible given a limit that corresponds to the maximum amount of material re-handled from the temporary waste dump to the final waste dump per year.

Before hauling material from the pit to the final waste dump, the tempo-

the final waste dump.

The NPV calculation is separated into the NPV of operational costs and the NPV of additional truck acquisition, per year.

The optimization target is based on the assumption that the best way to reduce the NPV costs is to delay, as much as possible, the waste re-handling from the temporary waste dump to the final waste dump given the year in which the temporary dump must be completely removed and the maximum re-handling rate from the temporary to the final waste dump per year. The discussion of this assumption is important because it rary waste dump storage capacity must be completed.

The input parameters are the following: the block schedule, the maximum amount of mass hauled from the temporary waste dump to the final waste dump, the ending year when the temporary waste dump must be completely removed, and operational cost parameters.

does not reflect the lowest NPV cost for all scenarios. In some cases, the maximum re-handling rate occurs simultaneously with the maximum rate of waste sent from the pit to the final waste dump. This situation might demand the acquisition of trucks in an unbalanced hauling operation, especially after the temporary waste dump is completely removed and all equipment is focused on the pit to the final waste dump hauling operation. For these cases, it is expected that the algorithm user explores the parameter that controls the maximum re-handling rate. Further discussion and examples will be presented in the results section. to the final waste dump. The report is given by year.

The waste haulage schedule from the pit to the temporary waste dump, from the pit to the final waste dump, and re-handling from the temporary to the final waste dump.

The NPV calculation is separated into the NPV of operational costs and the NPV of additional truck acquisition, per year.

The optimization target is based on the assumption that the best way to reduce the NPV costs is to delay, as much as possible, the waste re-handling from the temporary waste dump to the final waste dump given the year in which the temporary dump must be completely removed and the maximum re-handling rate from the temporary to the final 
waste dump per year. The discussion of this assumption is important because it does not reflect the lowest NPV cost for all scenarios. In some cases, the maximum re-handling rate occurs simultaneously with the maximum rate of waste sent from the pit to the final waste dump. This situation might demand the acquisition of trucks in an unbalanced hauling operation, especially after the temporary waste dump is completely removed and all equipment is focused on the pit to the final waste dump hauling operation. For these cases, it is expected that the algorithm user explores the parameter that controls the maximum re-handling rate. Further discussion and examples will be presented in the results section.

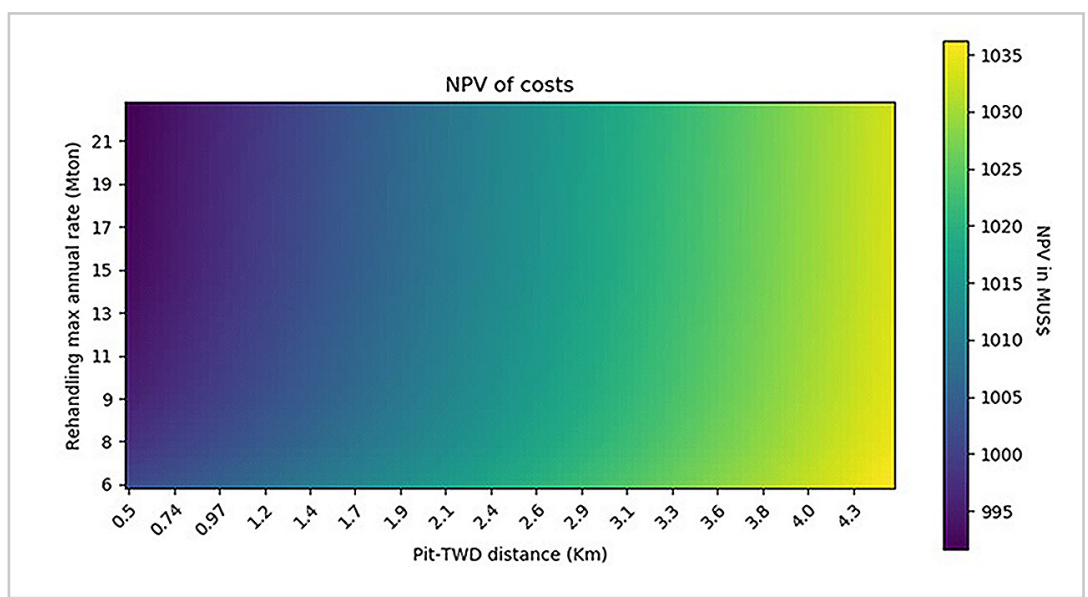

Figure 3 - NPV of costs behaviour considering the re-handling annual rate and distance from the pit to temporary waste dump (TWD) variation. No additional equipment acquisition is considered.

The dark blue areas represent lower NPV cost values, which means more attractive economic scenarios. However, this is an unrealistic situation as it is not possible to consider a higher re-handling rate without acquiring and allocating more equipment to deal with re-handling large masses of waste. The higher the re-handling rate is, the more trucks that need to be purchased, with consequently a higher cost, as observed in Figure 4.

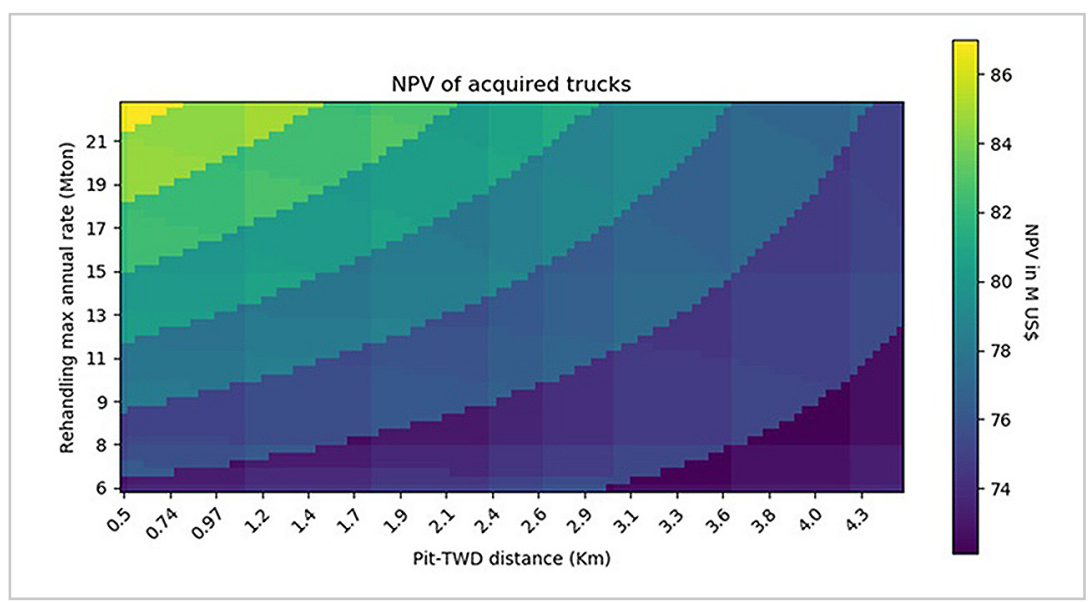

Figure 4 - Truck acquisition NPV cost behaviour considering the re-handling annual rate and distance from the pit to temporary waste dump (TWD) variation.

The darkest blue regions represent an NPV cost reduction of $2.5 \%$ compared to the base case, which was achieved mainly with closer temporary dumps to the pit (from 0.5 to $0.8 \mathrm{~km}$ ) associated with some specific annual re-handling rates providing balanced truck operations.

By merging Figure 3 and Figure 4, we can observe the relationship among these three variables (distance from pit to temporary dump, re-handling rate and number of required trucks), as seen in Figure 5. The light green line represents the NPV behaviour for the base case; therefore, any point in the left side of this line has a lower NPV cost than the base case, meaning that MSDS is a feasible method when locating the temporary dump no farther than approximately 3.3 $\mathrm{km}$ from the pit exit for any re-handling annual rate within the tested range.

The darkest blue regions represent an NPV cost reduction of $2.5 \%$ compared to the base case, which was achieved mainly with closer temporary dumps to the pit (from 0.5 to $0.8 \mathrm{~km}$ ) associated with some specific annual re-handling rates providing balanced truck operations.
By merging Figure 3 and Figure 4, we can observe the relationship among these three variables (distance from pit to temporary dump, re-handling rate and number of required trucks), as seen in Figure 5. The light green line represents the NPV behaviour for the base case; therefore, any point in the left side of this line has a lower NPV cost than the base case, meaning that MSDS is a feasible method when locating the temporary dump no farther than approximately $3.3 \mathrm{~km}$ from the pit exit for any re-handling annual rate within the tested range. 


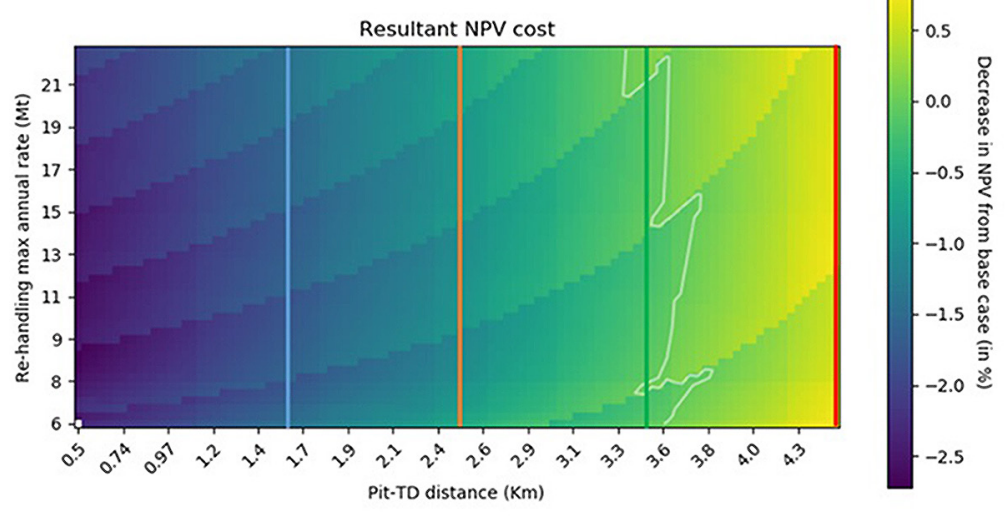

Figure 5 - Resultant NPV cost behaviour for the MSDS method compared

to the base case (light green line) considering the distance to TWD, annual re-handling rate and number of required trucks. Vertical lines (blue, orange, green and red) represent selected scenarios with a fixed pit-TD distance.

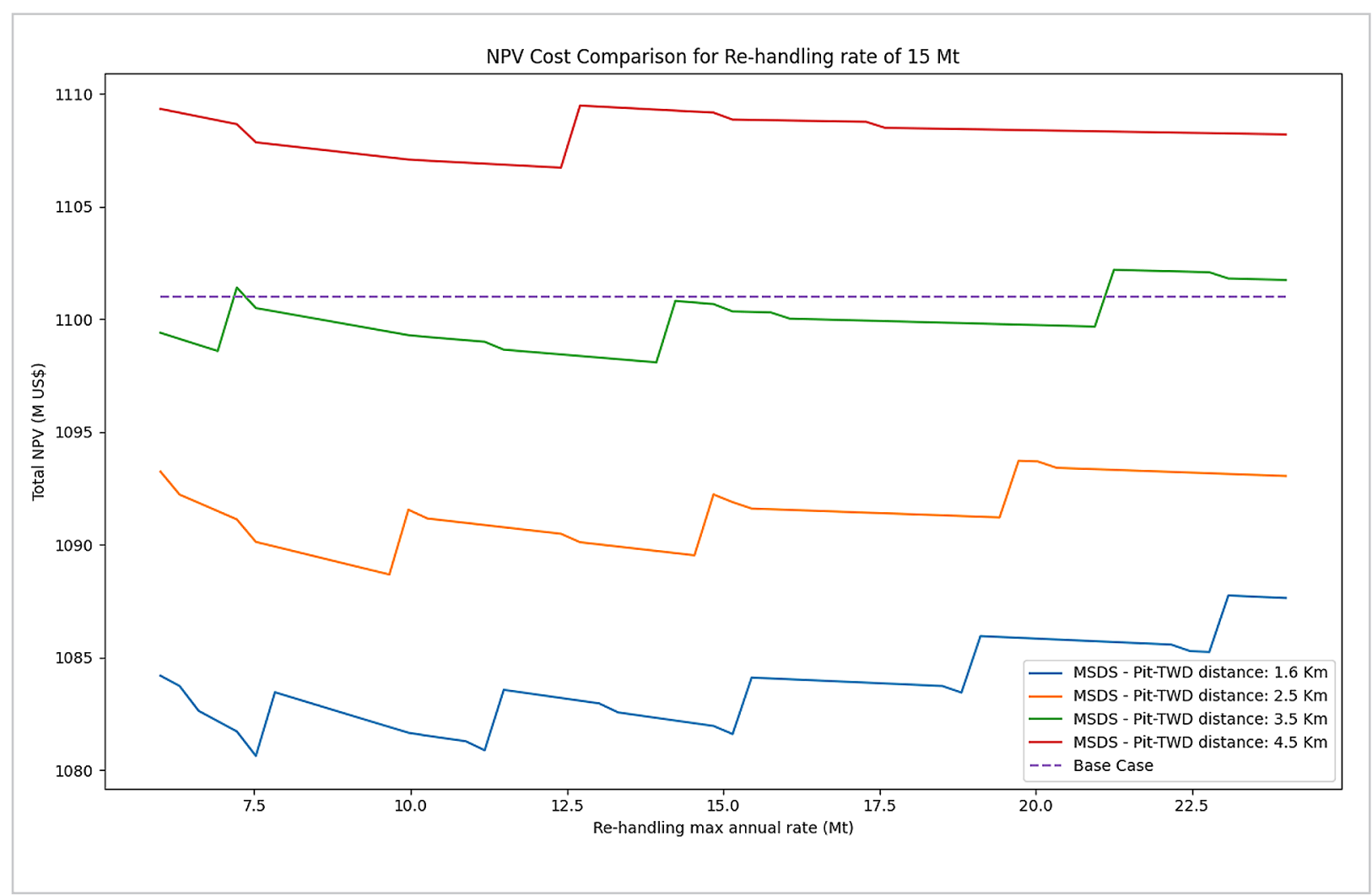

Figure 6 - Total NPV cost behaviour for four different distance scenarios from the pit to temporary dump.

\section{Discussion}

Observing the results shown in Figure 3 (operational costs) and 4 (truck acquisition), it is possible to observe a reverse behaviour regarding NPV cost regarding the re-handling rate and distance from the pit exit to the temporary waste dump. As expected, higher re-handling rates will require more trucks; however, locating the temporary dump closer to the pit exit could also result in an increase in the number of required trucks. For example, placing the temporary dump too close to the pit will increase the second stage of haulage distance from the temporary dump to the final dump destination. This situation associated with a high rehandling rate will result in more trucks to be acquired.

Choosing the period to start and finish re-handling operations is a key decision, and it is directly related to the re-handling rate. The algorithm always considers the re-handling operation ending in the 10th year, so the re-handing rate will dictate when this operation will begin.

There is a circular wave pattern in
Figure 4, which is associated with the truck utilization factor and availability. If the re-handling rate and/or temporary dump distance are slightly increased, an abrupt increase in NPV cost might occur. This increase is explained by the necessity to purchase an additional truck, which will cause a decrease in the utilization factor and in an unbalanced excavation/ haulage operation (exceeding haulage capacity at the right moment the new truck is added to the fleet).

The combination of both behaviours 
shown in Figure 5 gives us a more realistic overview of possible outcomes and relationships between variables. The indented and circular wave patterns are the result of the truck acquisition NPV cost, which causes a spike effect for any case while increasing the re-handling rate.

It is interesting that the best possible MSDS cases (dark blue areas) are not necessarily related to extreme values of the variables, as it would be expected. For instance, it is intuitive to think that setting the temporary waste dump as close as possible to the pit exit and a higher re-handling rate would provide the lowest NPV cost, which is not seen

\section{Conclusion}

This study provided information that suggests the viability of the MSDS method using waste re-handling, under a strategic planning perspective, opening new operational alternatives in mining industry. These results oppose a well-known mining paradigm, which states that material re-handling will always increase operational costs, considering it is something to be avoided at all costs. Analysing the case study from an economic perspective using NPV, MSDS demonstrated to be feasible when the temporary dump is located up to $3.3 \mathrm{~km}$ from the pit exit (considering a final dump located at $5 \mathrm{~km}$ away from the pit exit), which provides a wide and flexible range for the re-handling operation and yet having results that show a better economic scenario than the traditional approach.

Reducing the final dump distance from the pit exit will also shorten the MSDS feasibility range, which means in Figure 5.

The most attractive economic scenarios, that minimize the NPV cost, are achieved using combinations of rehandling rates and distance from the pit to the temporary dump. This behaviour can be better visualized in Figure 6 . All MSDS lines have steps when progressively increasing the re-handling rate, but they differ in the frequency between steps. Each peak in the curves represents the combination of a haulage distance and increases in re-handling rates, requiring the acquisition of one extra truck at each jump in the graphs. The blue line $(1.6 \mathrm{~km}$ from the pit exit to temporary dump) has a higher frequency of steps due to a longer distance from the temporary dump to the final dump. The longer haulage distance for the re-handled material transportation makes the number of required trucks more sensitive to changes in re-handling rates, which causes the steps to be more frequent. On the other hand, the green and red lines (with $3.5 \mathrm{~km}$ and $4.5 \mathrm{~km}$ from the pit exit to the temporary dump, respectively) represent the shorter haulage distance from the temporary dump to the final dump, with less frequent steps, causing a less sensitive required number of trucks. that the re-handling operation must be even more precise and less forgiving, however economically favourable. In addition, the MSDS method provides other advantages:

Planners will gain more time to make decisions regarding the final dump location and site preparation, allowing the collection of important operational data that might aid other strategic decisions during ramp-up periods.

Furthermore, capital expenditure (CAPEX) reduction during the first years (i.e., less equipment to purchase) provides a more favourable and less risky investment scenario, given the fluctuation of commodities and markets, that might generate a level of uncertainty putting the mining project at risk. In this case study, it was shown that MSDS provided an additional 2-year period before sending waste to the final dump. In the meantime, ex- perience and operational data can be obtained, providing a valuable resource for planners and decision makers.

From the environmental perspective, the MSDS approach also provides a strategic waste management flexibility to change waste dump sites by an in-pit disposal, which significantly reduces environmental impacts. At a certain point in time, re-handling can be considered viable and used to backfill the pit instead of sending the material to the final dump and impacting an additional area. Future mining will not tolerate any further environmental footprints other than what is strictly necessary.

Further investigations are still on course to understand cause/effect relationships with other variables to better define contour conditions to consider MSDS as a definitely feasible alternative method for managing and optimizing waste dumping and sequencing.

\section{References}

ASAD, W. A.; DIMITRAKOPOULOS, R. Optimal production scale of open pit mining operations with uncertain metal supply and long-term stockpiles. Resources Policy, v. 37, n.1, p. 81-89, 2012. DOI: https://doi.org/10.1016/j. resourpol.2011.12.002

ASKARI NASAB, H.; BEN-AWUAH, E. Integration of oil sands mine planning and waste management using goal programming. In: APCOM SYMPOSIUM - Application of computers and operations research in the minerals industry, 35th, 2011, Wollongong, Australia. Proceedings [...]. [S. l.]: AusIMM, 2011. p. 329-350.

ASKARI-NASAB, H.; EIVAZY, H.; TABESH, M.; BADIOZAMANI, M. M. A mathematical programming model for open pit short-term production scheduling. In: SME ANNUAL MEETING AND EXHIBIT; CMA NATIONAL WESTERN MINING CONFERENCE, 113th, 2011, Denver, Colorado. Proceedings [...]. [S. 1.]: SME, 2011. p. 213-220.

CACCETTA. L.; HILL, S. P. An application of branch and cut to open pit mine scheduling. Journal of Global Optimization, v. 27, p. 349-365, 2003.

DAGDELEN, K. Open pit optimization - strategies for improving economics of mining projects through mine planning. In: INTERNATIONAL MINING CONGRESS AND EXHIBITION OF TURKEY, 17 th, 2001, Ankara.

Proceedings [...]. Ankara: Chamber of Mining Engineers of Turkey, 2001. p. 117-122.

DEUTSCH, M.; DEUTSCH, C. V. An open source 3d Lerchs Grossmann pit optimization algorithm to facilitate 
uncertainty management. CCG Annual Report, v. 15, p. 1-6, 2013.

DEUTSCH, M.; GONZÁLEZ, E.; WILLIAMS, M. Using simulation to quantify: Uncertainty in ultimate-pit limits and inform infrastructure placement. Mining Engineering, v. 67, n. 12, p. 49-55, 2015.

DIMITRAKOPOULOS, R.; RAMAZAN, S. Uncertainty-based production scheduling in open pit mining. Transactions of the Institutions of Mining and Metallurgy, Section A: Mining Technology, v. 316, n. 03, p. 106-112, 2003.

DIMITRAKOPOULOS, R.; MARTINEZ, L.; RAMAZAN, S. A maximum upside / minimum downside approach to the traditional optimization of open pit mine design. Journal of Mining Science, v. 43, n. 1, p. 81-90, 2007.

ELKINGTON, T.; DURHAM, R. Integrated open pit pushback selection and production capacity optimization. Journal of Mining Science, v. 47, n. 2, p. 177-190, 2011.

ESPINOZA, D.; GOYCOOLEA, M.; MORENO, E.; NEWMAN, A. MineLib: a library of open pit mining problems. Annals of Operations Research, v. 206, p. 93-114, 2013.

FU, Z.; LI, Y.; TOPAL, E.; WILLIAMS, D. J. A new tool for optimisation of mine waste management in potential acid forming conditions. In: TAILINGS AND MINE WASTE MANAGEMENT FOR THE 21ST CENTURY, Sydney, Australia, 27-28 July, 2015. Proceedings [...]. Jolimont, WA, Australia: AusIMM, 2015.

FU, Z.; TOPAL, E.; ERTEN, O. A modified software tool for mine waste rock dump planning. In: AusIMM OPEN PIT OPERATORS' CONFERENCE, 9 th, 2016, Kalgoorlie, Western Australia, Australia. Proceedings [...]. [S. l.]: AusIMM, 2016. p. 229-242.

GRASKOKI, S.; CRAIG, S.; MYBURGH, C. Dynamic Pit and waste dump schedule optimisation and Tropicana Gold Mine. In: WORLD GOLD CONFERENCE, 2013, Brisbane. Proceedings [...]. [S. l.]: AusIMM, 2013. p. 121-127.

HEKMAT, A.; OSANLOO, M.; SHIRAZI, A. M. New approach for selection of waste dump sites in open pit mines. Mining Technology, v. 117, n.1, p. 24-31, 2008. DOI: https://doi.org/10.1179/174328608X343768.

KUCKARTZ, B. T.; PERONI, R. L. Multi-stage dumping sequence: a new approach for waste disposal. In: MUELLER, C. et al. (ed.). Mining Goes Digital. London: CRC Press, 2019. v. 3, p. 257-263.

LAMBERT, W. B.; BRICKEY, A.; NEWMAN, A. M.; EUREK, K. Open-Pit Block-Sequencing Formulations: a tutorial. INFORMS Journal on Applied Analytics, v. 44, n. 2, p. 127-142, 2014. DOI: https://doi.org/10.1287/ inte.2013.0731.

LEITE, A.; DIMITRAKOPOULOS, R. Stochastic optimisation model for open pit mine planning: application and risk analysis at copper deposit. Mining Technology, v. 116, n. 3, p. 109-118, 2007. DOI: https://doi. org/10.1179/174328607X228848.

LI, Y.; TOPAL, E.; WILLIAMS, D. Waste rock dumping optimisation using mixed integer programming (MIP). International Journal of Mining, Reclamation and Environment, v. 27, n. 6, p. 425-436, 2013. DOI: https://doi.org/10.1080/17480930.2013.794513.

LI, Y.; TOPAL, E.; RAMAZAN S. Optimising the long-term mine waste management and truck schedule in a large-scale open pit mine. Mining Technology, v. 125, n. 1, p. 35-46, 2016. DOI: http://doi.org/10.1080/1474 9009.2015.1107343.

LI, Y.; TOPAL, E.; WILLIAMS, D. J. Mathematical approach for better mine waste rock dumping management. In: LIFE-OF-MINE CONFERENCE, Brisbane, Australia, 2012. Proceedings [...]. Brisbane: AusIMM, 2012. p. 207-214.

LIZOTTE, Y.; BONATES, E. Truck and shovel dispatching rules assessment using simulation. Mining Science and Technology, v. 5, n. 1, p. 45-58, 1986. DOI: https://doi.org/10.1016/S0167-9031(87)90910-8.

ORTIZ, J. P.; SHUKLA, S. K. Methodology for a dump design optimization in large-scale open pit mines. Cogent Engineering, v. 4, n. 1, p. 1-11, 2017. DOI: https://doi.org/10.1080/23311916.2017.1387955.

RAMAZAN, S.; DIMITRAKOPOULOS, R. Production scheduling with uncertain supply: a new solution to the open pit mining problem. Optimization and Engineering, v. 14, p. 361-380, 2013. DOI: https://doi.org/10.1007/ s11081-012-9186-2.

ZINCK, J. Emerging technologies in mine waste management. In: INTERNATIONAL SIMPOSIUM ON WASTE PROCESSING AND RECYCLING IN MINERAL AND METALLURGICAL INDUSTRIES, 5th, 2004, Ontario. Proceedings [...]. [S. l.: s. n.], 2004. p. 50-66.

Received: 30 June 2019 - Accepted: 31 December 2020. 